\title{
Laboratory study on efficacy of etoxazole formulation having insect growth regulatory activity against the poultry red mite, Dermanyssus gallinae
}

\author{
Takako Murano ${ }^{1)}$, Yosuke Hashimoto ${ }^{2)}$ and Yoshiko TAmura ${ }^{2)}$ \\ 1) Chiba Prefectural Livestock Research Center, 16-1 Yachimata he, Yachimata-shi, Chiba, 289-1113 Japan \\ ${ }^{2)}$ Research and Development Division, Yashima-Sangyo Co., Ltd., 6-14-10, \\ Futago, Takatsu-ku, Kawasaki-shi, Kanagawa, 213-0007 Japan
}

(Received: 26 October 2006; Accepted: 19 March 2007)

\begin{abstract}
The efficacy of etoxazole emulsifiable concentrate (etoxazole EC) which has insect grow th regulatory activity against Dermanyssus gallinae, was studied in laboratory. Etoxazole EC did not show acaricidal effects against adult mites. At 2,500-fold or less dilution rates, etoxazole EC showed inhibitiory effects on hatchability of eggs and molting to the first instar nymphs. Hatchability and molting rate were less than $30 \%$ and $0 \%$, respectively. All of the hatched larvae died within one or two days after hatching. The efficacy of etoxazole EC against $D$. gallinae lasted for at least five months after treatment in the laboratory conditions. The same experiment of etoxazole EC was carried out against D. gallinae collected at two different locations to examine the location-related difference in efficacy, and almost similar results were obtained. The above results suggest that etoxazole EC will be an effective agent in controlling $D$. gallinae.
\end{abstract}

Key words: Dermanyssus gallinae, etoxazole EC, insect growth regulator

\section{INTRODUCTION}

Northern fowl mite Ornithonyssus sylviarum Canestrini et Fanzago, 1877 has been the most serious ectoparasites of poultry at the poultry farming in Japan. In recent years, outbreak of red poultry mite Dermanyssus gallinae De Geer, 1778 has become the problem in all parts of Japan. Dermanyssus gallinae ranges in all the continents other than Antarctica. Dermanyssus gallinae has been the problem in Europe for long period, and many studies have been reported. Dermanyssus gallinae hides in a cage or an egg receiver in daytime. In night, the mites climb up on a chicken body and then suck blood. Sucking blood causes anemia in chicken, leading damages to chicken such as de- crease of egg-laying rate and death in sever case (Wood, 1917; Suzuki, 1988; Cosoroaba, 2001; Ezaki et al., 2002; Pilarczyk et al., 2004; Adachi, 2006). It is also a possible vector of bacterial and viral disease agents (Valiente et al., 2005). Furthermore, the mites may attack humans. Signs of intense pruritus found particularly on exposed areas of the bodies of the people taking care of the flock suggested a mite invasion (Cencek et al., 2000).

The use of commercial acaricides is a common and effective way of controlling D. gallinae. However, development of resistance of $D$. gallinae to those commercial acaricides has become the global problem (Zeman and Zelezny, 1985; Zeman et al., 1986; Cooper and Cobb, 1987; Zeman, 1987; Hoglund et al., 1995; Beugnet et al., 1997; Fiddes et al., 2005). As the similar 
problem is concerned also in Japan, the authors searched the susceptibility of $D$. gallinae to commercial acaricides on a nationwide scale and found $D$. gallinae resistant to many acaricides (Murano et al., 2006). Five methods other than use of commercial acaricides were proposed for controlling $D$. gallinae by Chauve (1998) who considered that one of the methods using insect growth regulators (IGR) would become a highly contributing way in the future. In this study, Etoxazole, which has IGR activity against mites and ticks (Suzuki et al., 2001; Tamura et al., 2004; Nauen and Smagghe, 2006), was examined for its efficacy against $D$. gallinae in laboratory.

\section{Matelrials and Methods}

\section{Acaricides used in the study}

Etoxazole emulsifiable concentrate (containing $2.5 \%$ of etoxazole, YSI-0596W) (etoxazole EC), was obtained from Yashima-Sangyo Co., Ltd. Etoxazole EC was diluted with water at several dilution rates depending on the test purposes. For commercial acaricides, Sanmako wettable powder (containing 75\% of carbaryl, Sankyo Chemical Industries, Ltd.) (Sanmako), ETB emulsifiable concentrate (containing $4 \%$ of permethrin, Dainihon Jochugiku Co., Ltd.) (ETB) and Sumithion emulsifiable concentrate (containing 10\% of fenitrothion, Yashima-Sangyo Co., Ltd.) (Sumithion) were selected.

\section{Mites used in the study}

Dermanyssus gallinae used in Tests I to III were collected in Kyoto Prefecture (2003), and reared on hen at Chiba Prefectural Livestock Research Center. In Test IV, two wild colonies of $D$. gallinae, one collected in Fukushima Prefecture (2004) and the other in Niigata Prefecture (2004) were used.

\section{Susceptibility test}

Susceptibility of $D$. gallinae was evaluated according to the methods of Foulk and Matthysse (1963) and Arthur and Axtell (1983). Disposable Pasteur pipettes (0.5-cm inside diameter $\times 11-\mathrm{cm}$ length) were immersed into the acaricide solution for $1 \mathrm{~min}$, and allowed to dry standing vertically on blotting paper. The moisture in the pipette was volatilized using dryer so that the acaricide adsorbs on the internal surface of pipette. The wide end of Pasteur pipette was plugged with a cotton plug. Control pipettes were immersed in water containing no acaricide. Ten blood fed adult female mites were collected into the plugged pipette under reduced pressure and the open end of pipette was sealed with Hemato-Seal (Minato medical KF 120). The pipettes were kept at $25^{\circ} \mathrm{C}$ and $75 \% \mathrm{RH}$ for 24,48 and 72 hours in Tests I and II and for 24 and 48 hours in Tests III and IV before observing live/ dead status of mites in the pipettes under the microscope. A mite that stood still or was moribund, was judged to be inactive and struggle. A mite that was completely lethargic, was judged to be dead. A mite that belonged to any other condition than the above cases was judged to be alive. In addition, the number of laid eggs, the number of hatched larvae, and the number of larvae molting to the first nymphs were observed daily under the microscope for one week from the beginning of the incubation. At each concentration level, tests were performed in pentuplicate in Tests I and II and in triplicate in Tests III and IV.

The following four tests were performed according to the test purposes.

1) Test I: Study on effective dilution rates of etoxazole EC

With 1,000, 2,500, 5,000, 10,000, 25,000 and 50,000-fold diluted etoxazole EC aqueous solutions, acaricidal effect against adult mites, and inhibitions of hatching and molting were examined.

2) Test II: Comparison of efficacy of etoxazole EC and three commercial acaricides

Test II was performed with 50, 100, 200, 
400 and 800-fold diluted etoxazole EC aqueous solutions, 150-fold diluted Sanmako, 400-fold diluted ETB and 100fold diluted Sumithion. The concentrations for the commercial formulations were the stated maximum concentrations for the control of $D$. gallinae on the product labels.

3) Test III: Residual activity of etoxazole EC

Inhibitions of egg-laying, hatching and molting of mites in the etoxazole EC treated pipette stored for five months at 10, 50, 100 and 200-fold dilutions were examined.

4) Test IV: Efficacy of etoxazole against wild colony of $\mathrm{D}$. gallinae collected in other prefectures

With 100, 400 and 800-fold diluted etoxazole EC aqueous solutions, the efficacy of the agent against wild colony of D. gallinae collected in Fukushima and Niigata were studied.

\section{5) Statistical processing}

The 50\% inhibition concentration of hatching $\left(\mathrm{IC}_{50}\right)$ and $95 \%$ inhibition concentration of hatching $\left(\mathrm{IC}_{95}\right)$ of etoxazole were analyzed using a probit procedure (SAS Institute, 1985). The hatching rates, molting rates of larvae and mortalities were compared by Tukey's HSD test (Yoshida and Abe, 1984).

\section{RESULTS}

\section{Effective dilution rates of etoxazole EC}

Etoxazole EC showed almost no acaricidal effect against adult mites. Even at the maximum concentration of 1,000-fold dilution (25 ppm as etoxazole), the mortality of adult mites was only $8 \%$ at 48 hours after the treatment (Table 1).

The hatchability decreased as the concentration of etoxazole increased. The hatchability of mites was $68.5 \%$ and $16.1 \%$ when treated with etoxazole EC at dilution rates of 50,000 folds $(0.5 \mathrm{ppm})$ and 1,000 folds $(25 \mathrm{ppm})$, respectively. $\mathrm{IC}_{50}$ was $2.23 \mathrm{ppm}$ (approximately 10,000-fold dilution) and $\mathrm{IC}_{95}$ was 134.13 ppm (approximately 200 -fold dilution).

No molting from larvae to the first nymphs was observed when treated with etoxazole EC at 2,500-fold (10 ppm) or less dilution rates. Molting rate increased abruptly when treated with 50,000-fold diluted $(0.5 \mathrm{ppm})$ etoxazole EC solution. Mortality of larvae and first nymphs at 50,000 -fold dilution was $87.8 \%$. By the treatment with etoxazole EC at 25,000fold $(1 \mathrm{ppm})$ or less of dilution rates, all larvae and first nymphs died during the observation period (Table 2).

Comparison of efficacy of etoxazole EC and three commercial acaricides

At 48 hours after the treatment, the

Table 1. Mortalities of adult mites of Dermanyssus gallinae treated with etoxazole EC* at each dilution rate by contact test.

\begin{tabular}{|c|c|c|c|c|}
\hline \multirow{2}{*}{ Test compound } & \multirow{2}{*}{ Dilution rate } & \multirow{2}{*}{$\begin{array}{l}\text { Concentration of } \\
\text { active } \\
\text { ingredient }(\mathrm{ppm})\end{array}$} & \multicolumn{2}{|c|}{ Mortality (\%) } \\
\hline & & & After 24 hours & After 48 hours \\
\hline \multirow{6}{*}{ Etoxazole EC } & 1,000 & 25.0 & 6 & 8 \\
\hline & 2,500 & 10.0 & 0 & 0 \\
\hline & 5,000 & 5.0 & 0 & 2 \\
\hline & 10,000 & 2.5 & 0 & 2 \\
\hline & 25,000 & 1.0 & 0 & 2 \\
\hline & 50,000 & 0.5 & 0 & 4 \\
\hline Control (water) & - & - & 0 & 0 \\
\hline
\end{tabular}

\footnotetext{
* Etoxazole emulsifiable concentrate (containing $2.5 \%$ of etoxazole).
} 
Table 2. Number of eggs, hatchabilities of the eggs, molting rates to the first nymphs and mortalities of the larvae and the nymphs of the adult Dermanyssus gallinae treated with etoxazole EC*.

\begin{tabular}{lcccccc}
\hline \hline Test compound & Dilution rate & $\begin{array}{c}\text { Concentration } \\
\text { of active } \\
\text { ingredient } \\
\text { (ppm) }\end{array}$ & $\begin{array}{c}\text { Number of } \\
\text { eggs per a } \\
\text { female }\end{array}$ & $\begin{array}{c}\text { Hatch- } \\
\text { ability (\%) }\end{array}$ & $\begin{array}{c}\text { Molting rate } \\
(\%)\end{array}$ & $\begin{array}{c}\text { Mortality of } \\
\text { larvae and } \\
\text { nymphs }(\%)\end{array}$ \\
\hline Etoxazole EC & 1,000 & 25.0 & 24.8 & 16.1 & 0 & 100 \\
& 2,500 & 10.0 & 25.8 & 23.3 & 0 & 100 \\
Control (water) & 5,000 & 5.0 & 20.4 & 34.3 & 2.9 & 100 \\
& 10,000 & 2.5 & 22.2 & 58.6 & 6.2 & 100 \\
\end{tabular}

*Etoxazole emulsifiable concentrate (containing $2.5 \%$ of etoxazole).

Table 3. Mortalities of adult mites of Dermanyssus gallinae treated with etoxazole EC at each dilution rate.

\begin{tabular}{|c|c|c|c|}
\hline \multirow{2}{*}{ Test compound } & \multirow{2}{*}{ Dilution rate } & \multicolumn{2}{|c|}{ Mortality (\%) } \\
\hline & & After 24 hours & After 48 hours \\
\hline \multirow{5}{*}{ Etoxazle $\mathrm{EC}^{1)}$} & 50 & $0^{\mathrm{a}, 5)}$ & $10^{\mathrm{b}, 5)}$ \\
\hline & 100 & $2^{\mathrm{a}}$ & $6^{\mathrm{a}, \mathrm{b}}$ \\
\hline & 200 & $0^{\mathrm{a}}$ & $0^{\mathrm{a}}$ \\
\hline & 400 & $2^{\mathrm{a}}$ & $2^{\mathrm{a}, \mathrm{b}}$ \\
\hline & 800 & $2^{\mathrm{a}}$ & $2^{\mathrm{a}, \mathrm{b}}$ \\
\hline Sanmako $^{2)}$ & 150 & $44^{c}$ & $82^{\mathrm{d}}$ \\
\hline ETB $^{3)}$ & 400 & $58^{c}$ & $84^{\mathrm{d}}$ \\
\hline Sumithion $^{4 l}$ & 100 & $18^{\mathrm{b}}$ & $44^{c}$ \\
\hline Control (water) & - & $2^{\mathrm{a}}$ & $4^{\mathrm{a}, \mathrm{b}}$ \\
\hline
\end{tabular}

1) Etoxazole emulsifiable concentrate (containing $2.5 \%$ of etoxazole).

2) Sanmako wettable powder (containing $75 \%$ of carbaryl).

3) ETB emulsifiable concentrate (containing $4 \%$ of permethrin).

4) Sumithion emulsifiable concentrate (containing 10\% of fenitrothion).

5) Significant difference was observed between the different letters in the same column $(p<0.05)$.

mortalities of adult mites treated with 50fold diluted $(500 \mathrm{ppm})$ and 100 -fold diluted $(250 \mathrm{ppm})$ etoxazole EC solutions were $10 \%$ and $6 \%$, respectively. The mortalities of adult mites at other dilution rates were $0-2 \%$. The mortalities of mites treated with Sanmako (500 ppm), ETB $(100 \mathrm{ppm})$ and Sumithion (1,000 ppm) were $82 \%, 84 \%$ and $44 \%$, respectively, at 48 hours after the treatment. Commercial acaricides showed significantly higher mortality compared to those treated with etoxazole EC $(p<0.05)$ (Table 3$)$.

The hatchability increased as the dilution rates of etoxazole EC increased. However, the hatchability was only $26.4 \%$ when treated with 800-fold diluted etoxazole EC solution. The inhibition rate of hatching of etoxazole EC was significantly higher than those of three commercial acaricides and the control $(p<0.05)$. In addition, no molting to the first nymphs was observed by applications of etoxazole EC at any dilution rates. All of the hatched larvae treated with Sanmako and ETB died at the stage of larvae. In contrast $77.2 \%$ of larvae molted to the first nymphs, but all of the larvae and $97.8 \%$ of the first nymphs died during the observation period with Sumithion treatment (Table 4). 
Table 4. Number of eggs, hatchabilities of the eggs, molting rates to the first nymphs and mortalities of the larvae and the nymphs when the adult Dermanyssus gallinae were treated with etoxazole EC and three commercial acaricides.

\begin{tabular}{|c|c|c|c|c|c|}
\hline Test compound & Dilution rate & $\begin{array}{c}\text { Number of } \\
\text { eggs per female }\end{array}$ & $\begin{array}{c}\text { Hatchability } \\
(\%)\end{array}$ & $\begin{array}{c}\text { Molting rate } \\
(\%)\end{array}$ & $\begin{array}{c}\text { Mortality of } \\
\text { larvae and } \\
\text { nymphs (\%) }\end{array}$ \\
\hline \multirow[t]{5}{*}{ Etoxazole $\mathrm{EC}^{1)}$} & 50 & 30.3 & $12.2^{\mathrm{a}, 5)}$ & $0^{\text {a, 5) }}$ & $100^{\mathrm{b}, 5)}$ \\
\hline & 100 & 30.3 & $18.7^{\mathrm{a}, \mathrm{b}}$ & $0^{\mathrm{a}}$ & $100^{\mathrm{b}}$ \\
\hline & 200 & 28.7 & $19.8^{\mathrm{a}, \mathrm{b}}$ & $0^{\mathrm{a}}$ & $100^{\mathrm{b}}$ \\
\hline & 400 & 36.7 & $22.7^{\mathrm{b}}$ & $0^{\mathrm{a}}$ & $100^{\mathrm{b}}$ \\
\hline & 800 & 36.7 & $26.4^{\mathrm{b}}$ & $0^{\mathrm{a}}$ & $100^{\mathrm{b}}$ \\
\hline Sanmako ${ }^{2)}$ & 150 & 11.3 & $100^{c}$ & $0^{\mathrm{a}}$ & $100^{\mathrm{b}}$ \\
\hline $\mathrm{ETB}^{3)}$ & 400 & 2.0 & $100^{c}$ & $0^{\mathrm{a}}$ & $100^{\mathrm{b}}$ \\
\hline Sumithion ${ }^{4)}$ & 100 & 19.0 & $100^{c}$ & $77.2^{\mathrm{b}}$ & $100^{\mathrm{b}} \cdot 97.8$ \\
\hline Control (water) & - & 28.3 & $100^{c}$ & $100^{c}$ & $0^{\mathrm{a}}$ \\
\hline
\end{tabular}

1) Etoxazole emulsifiable concentrate (containing $2.5 \%$ of etoxazole).

2) Sanmako wettable powder (containing $75 \%$ of carbaryl).

3) ETB emulsifiable concentrate (containing $4 \%$ of permethrin).

4) Sumithion emulsifiable concentrate (containing $10 \%$ of fenitrothion).

5) Significant difference was observed between the different letters in the same column $(p<0.05)$.

Table 5. Number of eggs, hatchabilities of the eggs, molting rates to the first nymphs and mortalities of the larvae and the nymphs when the adult Dermanyssus gallinae were treated with etoxazole EC ${ }^{1)}$.

\begin{tabular}{|c|c|c|c|c|c|}
\hline $\begin{array}{l}\text { Months after } \\
\text { treatment }\end{array}$ & Dilution rate & $\begin{array}{l}\text { Number of laid } \\
\text { eggs per a } \\
\text { female }\end{array}$ & $\begin{array}{c}\text { Hatch- } \\
\text { ability(\%) }\end{array}$ & $\begin{array}{l}\text { Molting } \\
\text { rate }(\%)\end{array}$ & $\begin{array}{c}\text { Mortality of } \\
\text { larvae and } \\
\text { nymphs }(\%)\end{array}$ \\
\hline \multirow{4}{*}{0} & 10 & 6.3 & $0^{a, 2)}$ & $0^{\mathrm{a}, 2)}$ & $100^{\mathrm{b}, 2)}$ \\
\hline & 50 & 9.7 & $3.4^{\mathrm{a}}$ & $0^{\mathrm{a}}$ & $100^{\mathrm{b}}$ \\
\hline & 100 & 14.7 & $13.6^{\mathrm{b}}$ & $0^{\mathrm{a}}$ & $100^{\mathrm{b}}$ \\
\hline & 200 & 12.0 & $13.8^{b}$ & $0^{\mathrm{a}}$ & $100^{\mathrm{b}}$ \\
\hline \multirow{4}{*}{5} & 10 & 6.3 & $0^{\mathrm{a}}$ & $0^{\mathrm{a}}$ & $100^{\mathrm{b}}$ \\
\hline & 50 & 17.3 & $13.5^{\mathrm{b}}$ & $0^{\mathrm{a}}$ & $100^{\mathrm{b}}$ \\
\hline & 100 & 18.7 & $14.3^{\mathrm{b}}$ & $0^{\mathrm{a}}$ & $100^{\mathrm{b}}$ \\
\hline & 200 & 12.0 & $16.7^{\mathrm{b}}$ & $0^{\mathrm{a}}$ & $100^{\mathrm{b}}$ \\
\hline Control (water) & - & 16.3 & $100^{c}$ & $93.9^{\mathrm{b}}$ & $6.1^{\mathrm{a}}$ \\
\hline
\end{tabular}

1) Etoxazole emulsifiable concentrate (containing $2.5 \%$ of etoxazole).

2) Significant difference was observed between the different letters in the same column $(p<0.05)$.

Inhibition of egg-laying, hatching and molting of mites in the pipette stored for five months after the treatment with etoxazole EC

By the test performed on the day of treatment, etoxazole EC showed 100\% inhibition of hatching at 10-fold dilution rate. The hatchability increased as the dilution rates increased, and significantly low hatchability was observed at 10 and 50 -fold dilution rate. At all dilution rates, etoxazole showed 100\% inhibition of molting to the first nymphs. Compared to the above results hatchability at 50-fold dilution rate slightly increased at five months after treatment. The molting rate to the first nymphs and mortalities of larva and nymphs were not different between the pipettes on the day of treatment and those after five months (Table 5).

\section{Efficacy of etoxazole EC against two wild colonies of D. gallinae}

The acaricidal effect of etoxazole EC 
Table 6. Mortalities of adult mites of Dermanyssus gallinae collected in two different prefectures when treated with etoxazole $\mathrm{EC}^{1)}$ at each dilution rate by contact test.

\begin{tabular}{|c|c|c|c|c|}
\hline \multirow{2}{*}{ Prefecture } & \multirow{2}{*}{ Test compound } & \multirow{2}{*}{ Dilution rate } & \multicolumn{2}{|c|}{ Mortality (\%) } \\
\hline & & & After 24 hours & After 48 hours \\
\hline \multirow{4}{*}{ Fukushima } & Etoxazole EC & 100 & 0 & $6.7^{\text {a. 2) }}$ \\
\hline & & 400 & 0 & $6.7^{\mathrm{a}}$ \\
\hline & & 800 & 0 & $0^{\mathrm{a}}$ \\
\hline & Control (water) & - & 0 & $0^{\mathrm{a}}$ \\
\hline \multirow{4}{*}{ Niigata } & Etoxazole EC & 100 & 0 & $16.7^{\mathrm{b}}$ \\
\hline & & 400 & 0 & $16.7^{\mathrm{b}}$ \\
\hline & & 800 & 0 & $6.7^{\mathrm{a}}$ \\
\hline & Control (water) & - & 0 & $0^{\mathrm{a}}$ \\
\hline
\end{tabular}

1) Etoxazole emulsifiable concentrate (containing $2.5 \%$ of etoxazole).

2) Significant difference was observed between the different letters in the same column $(p<0.05)$.

Table 7. Number of eggs, hatchabilities of the eggs, molting rates to the first nymphs and mortalities of the larvae and the nymphs when the adult Dermanyssus gallinae collected in two different prefectures were treated with etoxazole EC.

\begin{tabular}{|c|c|c|c|c|c|c|}
\hline Prefecture & Test compound & $\begin{array}{l}\text { Dilution } \\
\text { rate }\end{array}$ & $\begin{array}{l}\text { Number of } \\
\text { eggs per a } \\
\text { female }\end{array}$ & $\begin{array}{c}\text { Hatchability } \\
(\%)\end{array}$ & $\begin{array}{l}\text { Molting } \\
\text { rate }(\%)\end{array}$ & $\begin{array}{c}\text { Mortality of } \\
\text { larvae and } \\
\text { nymphs }(\%)\end{array}$ \\
\hline \multirow{4}{*}{ Fukushima } & Etoxazole EC ${ }^{1)}$ & 100 & 22.7 & $2.9^{\mathrm{a}, 2)}$ & $0^{\mathrm{a}, 2)}$ & $100^{\mathrm{b}, 2)}$ \\
\hline & & 400 & 16.3 & $6.1^{\mathrm{a}}$ & $0^{\mathrm{a}}$ & $100^{\mathrm{b}}$ \\
\hline & & 800 & 13.7 & $4.9^{\mathrm{a}}$ & $0^{\mathrm{a}}$ & $100^{\mathrm{b}}$ \\
\hline & Control (water) & - & 15.3 & $100^{\mathrm{b}}$ & $100^{\mathrm{b}}$ & $0^{\mathrm{a}}$ \\
\hline \multirow{4}{*}{ Niigata } & Etoxazole EC & 100 & 23.7 & $1.4^{\mathrm{a}}$ & $0^{\mathrm{a}}$ & $100^{\mathrm{b}}$ \\
\hline & & 400 & 18.0 & $1.9^{\mathrm{a}}$ & $0^{\mathrm{a}}$ & $100^{\mathrm{b}}$ \\
\hline & & 800 & 31.7 & $0^{\mathrm{a}}$ & $0^{\mathrm{a}}$ & $100^{\mathrm{b}}$ \\
\hline & Control (water) & - & 25.3 & $98.7^{\mathrm{b}}$ & $100^{\mathrm{b}}$ & $0^{\mathrm{a}}$ \\
\hline
\end{tabular}

1) Etoxazole emulsifiable concentrate (containing $2.5 \%$ of etoxazole).

2) Significant difference was observed between the differnt letters in the same column $(p<0.05)$.

was slightly higher against adult mites collected in Niigata than those collected in Fukushima, but the mortality was only $16.7 \%$ at maximum (Table 6 ).

For both wild colonies of $D$. gallinae, the hatchabilities were in the single digits, and the inhibition rates of hatching of etoxazole EC at the dilution rates of 100 to 800 were significantly higher than control $(p<0.05)$. The molting rate to the first nymphs was $0 \%$, and all larvae died during the observation period when treated with etoxazole EC (Table 7).

\section{Discussion}

Since IGR exhibits an acaricidal effect by inhibiting hormone metabolism and chitin biosynthesis, killing effect of IGR cannot be expected in adult insects (Mitsui, 2000). Tebufenozide and methoxyfenozide, which are bisacylhydrazine compounds with molting hormone activity, lowered the hatchability of european corn borer Ostrinia nubilalis Hulmer and killed many freshly eclosed larvae because of molting disruption (Trisyono and Chippendale, 1997). In cat flea Ctenocephalides felis Bouche treated with pyriproxyfen and methoprene, which have juvenile hormone mimic activity, disintegration of laid eggs and death during embryogenesis and after eclosion were observed (Palma et al., 1993). Treat- 
ment of the imago of stable fly Stomoxys calcitrans Linnaeus and house fly Musca domestica Linnaeus with the chitin synthesis inhibitor, diflubenzuron, reduced the number of eggs laid and the hatchability (Wright and Spates, 1976).

It has been reported that etoxazole showed ovicidal and molting inhibitiory activities to two spotted spider mites Tetranychus urticae Koch at a low concentration, and hatching inhibition to aphids Myzus persicae Sulzer which acquired resistance to various acaricides (Suzuki et al., 2001). Etoxazole also has an inhibitory effect on oviposition and a killing effect against imagos of aphids by shrinking (Tanji et al., 1996). Furthermore etoxazole inhibited the molting of larvae and nymphs and the hatching of eggs of Haemaphysalis longicornis Neumann (Tamura et al., 2004). The mode of action of etoxazole in the arthropods described above is unknown. Nauen and Smagghe (2006) treated larvae of fall armyworms Spodoptera frugiperda J. E. Smith with etoxazole and suggested that the abnormal amount of chitin content in the integument caused by inhibition of chitin biosynthesis killed the larvae. The present test results confirmed that etoxazole causes reduction of the hatchability and subsequent death of all hatched larvae in D. gallinae, and that etoxazole may have effects on $D$. gallinae similar to those on spider mites and animal-parasitic ticks.

Etoxzole EC is thought to have persistent efficacy for at least five months in the laboratory conditions.

Application of pharmaceuticals with IGR activity to $D$. gallinae has not been reported previously in the world. In this study, we evaluated etoxazole as an candidate for controlling $D$. gallinae and obtained good results. In circumstances in which the resistance of $D$. gallinae to commercialized acaricides is increasing throughout the world, etoxazole will be a promising agent. Field tests are under planning for confirmation of practical potency.

\section{REFERENCES}

Adachi, S. 2006. Parasitic cases of Dermanyssus gallinae, the poultry red mite, on hen. Yokeino Tomo, Apr.: 60-65 (in Japanese).

Arthur, F. H. and Axtell, R. C. 1983. Susceptibility of northern fowl mites in North Carolina to five acaricides. Poult. Sci., 62: 428-432.

Beugnet, F., Chauve, C., Gauthey, M. and Beert, L. 1997. Resistance of the red poultry mite pyrethroids in France. Vet. Rec., 140: 577-579.

Cencek, T., Ziomko, I. and Majdanski, R. 2000. Acariasis attributed to the bird mite Dermanyssus gallinae. Medycynaryjan Weterynaryjna, 56: 11-116.

Chauve, C. 1998. The poultry red mie Dermanyssus gallinae (De Geer, 1778): current situation and future prospects for control. Vet. Parasitol., 79: 239-245.

Cooper, N. A. and Cobb, R. M. 1987. Use of flumethrin for the control of Dermanyssus gallinae in broiler breeder flocks. Aust. Vet. J., 64: 83.

Cosoroaba, I. 2001. Massive Dermanyssus gallinae invasion in battery-husbandry raised fowls. Rev. Med. Vet., 152: 89-96.

Ezaki, K., Nakamura, K. and Ishibashi, K. 2002. Two severe cases of hens caused by Dermanyssus gallinae invasion. Yokeino Tomo, Nov.: 46-49 (in Japanese).

Fiddes, M. D., Le Gresley, S., Parsons, D. G., Epe, C., Coles, G. C. and Stafford, K. A. 2005. Prevalence of the poultry red mite (Dermanyssus gallinae) in England. Vet. Rec., 157: 233-235.

Foulk, J. D. and Matthysse, J. G. 1963. Experiments on control of the northern fowl mite. J. Econ. Entomol., 56: 321-326.

Hoglund, J., Nordenfors, H. and Uggla, A. 1995. Prevalence of the poultry red mite, Dermanyssus gallinae, in different types of production systems for egg layers in Sweden. Poult. Sci., 74: 1793-1798.

Mitsui, T. 2000. Insect growth regulators based on disruption of insect cuticle formation. J. Pestic. Sci., 25: 150-164.

Murano, T., Namiki, K., Shiina, K., Ishihara, K. and Matsumoto, Y. 2006. Poultry red mites, Dermanyssus gallinae. J. Soc. Vet. Sci., 141: 141.

Nauen, R. and Smagghe, G. 2006. Mode of action of etoxazole. Pest Manag. Sci., 62: 379-382.

Palma, K. G., Meola, S. M. and Meola R. W. 1993. Mode of action of pyriproxyfen and methoprene on eggs 
of Ctenocephalides felis (Siphonaptera: Pulicidae). J. Med. Entomol., 30: 421-426.

Pilarczyk, B., Balicka-Ramisz, A., Ramisz, A. and Pajak, B. 2004. Influence of Dermanyssus gallinae on health and production in layers. Medycynaryjan Weterynaryjna, 60: 874-876.

SAS Institute. 1985. SAS User's Guide: Statistics. 956 pp., SAS Institute, Cary, NC.

Suzuki, J., Ishida, T., Shibuya, I. and Toda, K. 2001. Development of a new acaricide, Etoxazole. J. Pestic. Sci., 26: 215-223.

Suzuki, K. 1988. Damage cases of hens caused by massive Dermanyssus gallinae invasion and its measures. Yokeino Tomo, June: 46-49 (in Japanese).

Tamura, Y., Tsubaki, Y., Terada, Y., Kohmoto, M. and Kamio, T. 2004. The efficacy of etoxazole against Haemaphysalis longicornis (Acari; Ixodidae), as a tick control agent. Med. Entomol. Zool., 55: 303311.

Tanji, I., Tsukidate, Y. and Morikawa, C. 1996. Study of novel acaricide YI-5301 (2) Effects of some aphididae. Jpn. J. Appl. Entomol. Zool., 40: 90.

Trisyono, A. and Chippendale, G. M. 1997. Effect of the nonsteroidal ecdysone agonists, methoxyfenozide and tebufenozide, on the European corn borer (Lepidoptera: Pyralidae). J. Econ. Entomol., 90: 1486-1492.
Valiente Moro, C., Chauve, C. and Zenner, L. 2005. Vectorial role of some dermanyssoid mites (Acari, Mesostigmata, Dermanyssoidea). Parasite, 12: 99109.

Wood, H. P. 1917. The Chicken mite: Its life history and habits. In: Bulletin No. 553 (ed. Howard, L. O.). pp. 1-14, U. S. Department of Agriculture, Washington DC.

Wright, J. E. and Spates, G. E. 1976. Reproductive inhibition activity of the insect growth regulator TH6040 against the stable fly and the house fly: effects on hatchability. J. Econ. Entomol., 69: 365368.

Yoshida, M. and Abe, T. 1984. Statistical Method for Livestock Industry (The second edition). 320 pp., Japan Livestock Industry Association, Tokyo.

Zeman, P. 1987. Encounter the poultry red mite resistance to acaricides in Czechoslovakia poultry farming. Folia Parasitol., 34: 369-373.

Zeman, P., Kuntos, J., Domkar, P., Uridil, J., Plachy, J. and Homolac, M. 1986. Current methods of controlling Dermanyssus gallinae in Czechoslovakia. Veterinarstvi, 36: 375-376.

Zeman, P. and Zelezny, J. 1985. The susceptibility of the poultry red mite, Dermanyssus gallinae (De Geer, 1778), to some acaricides under laboratory conditions. Exp. Appl. Acarol., 1: 17-22. 